\title{
Caracterización sanitaria e identificación de los puntos de contaminación microbiológica en la cadena de comercialización pesquera en el puerto de Pucallpa, Ucayali, Perú
}

\section{Sanitary characterization and identification of microbial contamination points in the fishing marketing chain in the port of Pucallpa, Ucayali, Peru}

\author{
Juan Rondón E. ${ }^{1,4}$, Daphne Ramos D. ${ }^{2}$, Miguel Vilca L. ${ }^{2}$, Eduardo Salazar S. ${ }^{2}$, Yamili \\ Mendoza Q. ${ }^{1}$, Rosa González V. ${ }^{3}$
}

\section{Resumen}

\begin{abstract}
El objetivo del estudio fue caracterizar sanitariamente la cadena de comercialización pesquera e identificar los puntos de contaminación microbiológica desde el desembarque hasta la venta, en el puerto de Pucallpa, Ucayali, Perú. La pesca artesanal finaliza con el desembarque de botes de madera con motor. Los pescados son lavados en el agua del río, así como el material plástico y tinas dentro de los $150 \mathrm{~m}$ de la ribera. Los pescados son trasladados cubiertos con hielo picado, capas de plástico y cascarilla de arroz. Las instalaciones para la venta son de madera. No hay programas de desinfección ni sanitización del área y los residuos sólidos son eliminados en un sector aledaño. La indumentaria de trabajo no es utilizada por los manipuladores del pescado, pero lo usan algunos comercializadores primarios. Los parámetros físicoquímicos de las muestras de agua estaban dentro de los rangos normales, pero se detectó la presencia de coliformes, E. coli y Pseudomona sp en niveles elevados. En los pescados, los mesófilos estuvieron por encima al Límite Máximo permisible (LMP) en carne de bagre (Siluriforme spp); E. coli estuvo en bajos niveles en la carne de las tres especies evaluadas (boquichico [Prochilodus nigricans], palometa [Mylossoma duriventre] y bagre); Staphylococcus aureus estuvo presente en niveles bajos, pero por encima del LMP en bagres; Salmonella sp, Vibrio cholerae y $V$. parahemolyticus estuvieron ausentes. En instalaciones, mobi-
\end{abstract}

\footnotetext{
${ }^{1}$ Centro de Investigaciones IVITA, Universidad Nacional Mayor de San Marcos, Pucallpa, Perú

${ }^{2}$ Laboratorio de Salud Pública y Salud Ambiental, Facultad de Medicina Veterinaria, Universidad Nacional Mayor de San Marcos, Lima, Perú

${ }^{3}$ Laboratorio de Patología Aviar, Facultad de Medicina Veterinaria, Universidad Nacional Mayor de San Marcos, Lima, Perú

${ }^{4}$ E-mail: jrondone@unmsm.edu.pe
}

Recibido: 12 de febrero de 2019

Aceptado para publicación: 11 de diciembre de 2019

Publicado: 31 de marzo de 2020 
liarios y manos de los manipuladores se encontró $E$. coli y recuentos elevados de coliformes. Los resultados muestran un manejo artesanal con una bioseguridad deficiente en la cadena de comercialización pesquera y una contaminación microbiológica moderada, tanto en instalaciones y manipuladores como en los pescados.

Palabras clave: caracterización sanitaria, comercialización pesquera, puertos, Ucayali

\section{Abstract}

The aim of this study was to conduct the sanitary characterization of the fishing marketing chain and identify the points of microbiological contamination from landing to sale, in the port of Pucallpa, Ucayali, Peru. Artisanal fishing ends with the landing of wooden boats with motor. The fish are washed in the river water, as well as plastic material and tubs within $150 \mathrm{~m}$ of the riverbank. The fish are transferred covered with crushed ice, plastic layers and rice husk. The facilities for sale are made of wood. There are no programs to disinfect or sanitize the area and solid waste is disposed of in a nearby sector. Work clothing is not used by fishermen, but some primary marketers use it. The physicochemical parameters of the water samples were within the normal ranges, but the presence of coliforms, E. coli and Pseudomona sp at high levels was detected. In fish, mesophiles were above the Maximum Permissible Limit (MPL) in catfish meat (Siluriforme $\mathrm{spp}$ ); E. coli was at low levels in the meat of the three species evaluated (black prochilodus [Prochilodus nigricans], silver mylossoma [Mylossoma duriventre] and catfish); Staphylococcus aureus was present at low levels, but above the MPL in catfish, and Salmonella sp, Vibrio cholerae and V. parahemolyticus were absent. In facilities, furniture and hands of the fihermen was found $E$. coli and high counts of coliforms. The results show an artisanal management with poor biosecurity in the fishing marketing chain and a moderate microbiological contamination, both in facilities, in fishermen and in fish.

Key words: sanitary characterization, fishing commercialization, ports, Ucayali

\section{INTRODUCCIÓN}

La pesca es una de las actividades productivas más importantes en la Amazonia peruana, con un consumo per cápita anual aproximado de pescado de $15.4 \mathrm{~kg}$, indicador de su importancia para la alimentación de la población (Produce, 2015). La pesca genera un ingreso anual aproximado de US\$ $80 \mathrm{mi}-$ llones en la región amazónica; no obstante, dentro de la pesca para consumo, la de mayor relevancia, es la de subsistencia, con un volumen del $75 \%$ de pescado desembarcado anualmente (Tello y Bayley, 2001).
El puerto de Pucallpa es uno de los principales lugares de desembarco de pescado en la provincia de Coronel Portillo, región Ucayali. La comercialización de pescado generalmente es en estado fresco y está destinada mayormente al consumo local y regional, especialmente de especies como boquichico (Prochilodus nigricans), llambina (Potarmorhina altamazonica), chio chio (Psectrogaster rutiloides), bagre (Siluriforme), sardina (Triportheus angulatus) y palometa (Mylossoma duriventre) entre otros (IMARPE, 2017). 
La temperatura $\left(30 \pm 4{ }^{\circ} \mathrm{C}\right)$ y humedad promedio anual $(85 \pm 5 \%)$ de la zona influyen negativamente en la vida útil del pescado, acelerando su descomposición. Adicionalmente, se observan grandes deficiencias en la aplicación de las normas sanitarias elementales durante todo el proceso, desde la extracción hasta la venta al consumidor, disminuyendo la garantía del buen estado sanitario de estos productos, además de causar más del 70\% de las pérdidas totales (FAO, 2014).

El pescado en mal estado puede ocasionar serios problemas de salud al consumidor. Corrales et al. (2011) indican que los microorganismos bacterianos patógenos para el hombre que se trasmiten frecuentemente vía el pescado son Escherichia coli, Salmonella sp, Listeria monocytogenes y Staphylococcus aureus, debido a la contaminación con materia fecal del agua asociada al proceso de manipulación que sufre el pescado posterior a su captura. Adicionalmente, Barba et al. (2012) señalan que la contaminación del pescado con histamina desencadena procesos alérgicos.

Las deficiencias existentes en la cadena de comercialización pesquera incrementan el riesgo en la presentación de enfermedades transmitidas por alimentos (ETA), repercutiendo negativamente en las actividades comerciales. Dentro de las causales de pérdidas económicas tenemos los decomisos de productos en mal estado o que estando en buen estado son asociados con las ETA, así como la clausura de establecimientos que expenden alimentos, sean estos mercados o restaurantes (OMS, 2015). La Ley General de Pesca del Perú data de 2001, y establece que la actividad de procesamiento será ejercida cumpliendo las normas de sanidad, higiene y seguridad industrial, calidad y preservación del medio ambiente, con sujeción a las normas legales y reglamentarias pertinentes (FAO/OMS, 2015). En 2011, el Ministerio de la Producción emitió un Reglamento de Inspecciones y Sanciones Pesqueras y Acuícolas (PISPAC), que involucra la inspección en zonas de pesca, puntos de desembarque, embarcaciones pesqueras, centros de comercialización y cámaras frigoríficas, entre otros, relacionados a la conservación de especies y regulación de la pesca ilegal durante las vedas (PRODUCE, 2011); sin embargo, se observa una carencia de aplicación de medidas sanitarias en las zonas de desembarque de la región.

Es importante señalar que en 2016, el Organismo Nacional de Sanidad Pesquera (creado en el año 2013), emitió una Guía de Fiscalización Pesquera y Acuícola, y un Manual de Indicadores Sanitarios y de Inocuidad para los Productos Pesqueros y Acuícolas para el Mercado Nacional y de Exportación (SANIPES, 2016a,b); no obstante, debido a la falta de presupuesto no se ha podido instaurar en la región una filial consolidada, por lo que no hay una actualización de la información en los aspectos sanitarios en las actividades de comercialización pesquera. El presente estudio tuvo como objetivo caracterizar sanitariamente los puntos críticos de contaminación en la cadena de comercialización pesquera en el puerto de Pucallpa, Ucayali, Perú.

\section{Materiales y Métodos}

Se caracterizó sanitariamente la cadena de comercialización pesquera y se identificaron los puntos de contaminación microbiológica desde el desembarque hasta la venta, en el puerto de Pucallpa, Coronel Portillo, Ucayali. La primera fase se realizó recolectando los datos en el desembarcadero. En la segunda fase se recolectaron muestras en el mismo desembarcadero. El procesamiento de las muestras se realizó en la Unidad de Diagnóstico del Laboratorio de Sanidad Animal del Centro de Investigación IVITA, Pucallpa. El estudio se realizó entre junio de 2017 y marzo de 2018. 


\section{Medidas Sanitarias y Prácticas de Mani- pulación}

Se reconocieron las características geográficas del desembarcadero y ubicación de los lugares de expendio de productos hidrobiológicos en los lugares aledaños en el puerto. La caracterización de las medidas sanitarias se realizó mediante una descripción de los aspectos involucrados de bioseguridad en la cadena de comercialización pesquera, distribución de áreas para las actividades desarrolladas, mobiliario e instalaciones existentes, programas de limpieza o desinfección de áreas, indumentaria de trabajo, procedimientos para el desembarque, expendio, almacenamiento y conservación de los productos y, finalmente, la disposición de los residuos sólidos.

La caracterización de las prácticas de manipulación de los productos pesqueros se realizó mediante una descripción de los aspectos involucrados (indumentaria de trabajo, aseo personal y procedimientos de manipulación de los productos) durante y después del desembarque, y en los lugares de expendio para los comercializadores primarios existentes en el puerto.

\section{Puntos Críticos de Contaminación Microbiológica}

Se tomaron muestras de los puntos críticos en la cadena de comercialización para el análisis en laboratorio.

a) Análisis de una muestra representativa según la Norma de SANIPES (2016a) de las tres especies de peces más comercializados en los lugares de expendio. Este comprende:

- Análisis microbiológico de 30 peces de cada una de las tres especies con mayor desembarque y de mayor comercialización en el puerto (boquichico. palometa y bagre para el descarte de seis agentes bacterianos comprometidos en la seguridad alimentaria: Aerobios mesófilos, Escherichia coli, Staphylococcus aureus, Salmonella spp, Vibrio cholerae y Vibrio parahemolyticus, considerándolos como muestreo por lote, siguiendo la metodología descrita por Da Silva et al. (2013).

- Análisis parasitológico de 30 peces (10 por especie) elegidos al azar, para determinar peces visiblemente parasitados, aplicando la metodología descrita por Conroy (2006).

b) Determinación del $\mathrm{pH}$ de la carne de 30 peces en los lugares de expendio (10 por especie) elegidos al azar, para obtener información sobre la condición de la carne de pescado (FAO, 1998).

c) Análisis del agua, teniendo en cuenta tres puntos críticos para el muestreo: zona de desembarco del pescado, a 50 de la orilla del río (donde lavan el pescado antes del desembarque), y a $150 \mathrm{~m}$ de la orilla del río. Se recolectaron tres muestras en cada punto descrito y se realizaron los siguientes análisis:

- Análisis microbiológico: Determinación del Número más Probable (MNP) para coliformes totales, coliformes termo-tolerantes y la detección de patógenos como Pseudomona sp y Escherichia coli (Da Silva et al., 2013).

- Análisis parasitológico, siguiendo el método señalado por SMEWW et al. (2012).

- Análisis fisicoquímico, siguiendo el método señalado por SMEWW et al. (2012).

d) Análisis microbiológico de las instalaciones presentes en los desembarcaderos y áreas de expendio (interior de embarcaciones, muros de contención de madera o concreto, mesas, plásticos protectores, bandejas o tinas), mediante un muestreo aleatorio al azar en el $50 \%$ del total o un mínimo de 10 muestras de unidades en cada instalación o área de expendio. Se determinaron las Unidades Formadoras de Colonias (UFC) de coliformes por área de superficie regular o irregular, y la determinación de patógenos más frecuentes: E. coli y Salmonella sp (MINSA, 2007; Da Silva et al., 2013). 
e) Análisis microbiológico de las manos de personas involucradas en la cadena de comercialización en cada puerto (manipuladores de pescados en el desembarque, acopiadores y vendedores o comercializadores primarios). Se recolectaron 10 muestras y se determinaron las UFC de coliformes por manos, y de los patógenos más frecuentes: E. coli y Salmonella sp (MINSA, 2007; Da Silva et al., 2013).

\section{Resultados}

\section{Primera Fase}

\section{Caracterización del lugar}

- El desembarcadero de la capitanía de Pucallpa, ubicado en la ribera del río Ucayali, tiene una extensión aproximada de $250 \mathrm{~m}$, y la actividad depende de la creciente o vaciante del río.

- El mayor desembarque se produce en los meses de vaciante (junio - agosto).

- La pesca artesanal se realiza en botes de madera con motor. El lavado del pescado se realiza a $150 \mathrm{~m}$ de la ribera del río. Así mismo, enjuagan los plásticos y tinas en agua de la orilla.

- La comercialización primaria se desarrolla cercana a las riberas del río (entre 10 y $20 \mathrm{~m})$.

- No existe separación de áreas desde el desembarque hasta el expendio.

- El puerto no cuenta con una infraestructura para el desembarque.

- El puerto cuenta para la comercialización primaria con una infraestructura de madera con techos de calamina y mesas de madera (el $20 \%$ están cubiertos por una plancha de fornica y en el resto están cubiertas por plásticos).

Caracterización de las medidas sanitarias

- Los peces son trasladados en botes, mayormente cubiertos con hielo picado, capas de plástico y cascarilla de arroz.
En algunos casos usan un cooler grande.

- La venta en zonas aledañas a los desembarcaderos cuenta con instalaciones de madera.

- $\quad$ No se maneja un programa de desinfección ni sanitización del área.

- Los residuos sólidos son eliminados en un sector aledaño a la zona de comercialización y son recolectados dos veces por semana.

Caracterización de las prácticas de manipulación

- Las personas involucradas en la manipulación antes y después del desembarque no usan indumentaria de trabajo (solo botas); sin embargo, algunos comercializadores primarios usan indumentaria (guantes, mandil y botas). No cuentan con agua potable en el lugar de venta, pero se abastecen de un grifo común para el lugar de expendio. Los comercializadores secundarios del mercado aledaño usan indumentaria de trabajo (mandil, botas, guantes) y cuentan con agua potable.

- Los comercializadores ocasionalmente usan el agua de las riberas del río para lavar utensilios, tinas y plásticos, tanto para el desembarque como para la comercialización primaria.

- El procedimiento de manipulación de los productos pesqueros comprende el eviscerado y el lavado por parte de los comercializadores primarios, quienes eliminan las vísceras en bolsas de plástico o baldes de $20 \mathrm{~L}$ y los almacenan al lado de las mesas para finalmente llevarlos a una esquina de toda la zona de venta para eliminarlos.

\section{Segunda Fase}

Las bacterias mesófilas estuvieron por encima del Límite Máximo Permisible (LMP) en carne de bagre; E. coli estuvo presente en bajos niveles en las tres especies, siendo mayor en bagres; Staphylococcus 
Cuadro 1. Evaluación microbiológica de la carne de tres especies de peces en el puerto de Pucallpa, Ucayali, Perú

\begin{tabular}{|c|c|c|c|c|c|c|c|}
\hline \multirow[t]{2}{*}{ Microorganismo } & \multicolumn{2}{|c|}{$\begin{array}{l}\text { Boquichico } \\
\text { (Prochilodus } \\
\text { nigricans) }\end{array}$} & \multicolumn{2}{|c|}{$\begin{array}{l}\text { Palometa } \\
\text { (Mylossoma } \\
\text { duriventre) }\end{array}$} & \multicolumn{2}{|c|}{$\begin{array}{c}\text { Bagre } \\
\text { (Siluriforme sp) }\end{array}$} & \multirow[t]{2}{*}{$\begin{array}{c}\text { Límite máximo } \\
\text { permisible / g }\end{array}$} \\
\hline & $\mathrm{n}$ & $\mathrm{c}$ & $\mathrm{n}$ & $\mathrm{c}$ & $\mathrm{n}$ & $\mathrm{c}$ & \\
\hline $\begin{array}{l}\text { Aerobios mesófilos } \\
\text { totales } \\
\quad \text { (UFC/g) }\end{array}$ & 5 & 0 & 5 & 0 & 5 & 5 & $\begin{array}{c}\mathrm{m}\left(5 \times 10^{5}\right), \mathrm{M} \\
\left(10^{6}\right) \\
(n: 5, c: 2)\end{array}$ \\
\hline $\begin{array}{l}\text { Escherichia coli } \\
\quad(\mathrm{NMP} / \mathrm{g})\end{array}$ & 5 & 0 & 5 & 1 & 5 & 3 & $\begin{array}{c}\mathrm{m}(10), \mathrm{M}\left(10^{2}\right) \\
(n: 5, c: 3)\end{array}$ \\
\hline $\begin{array}{l}\text { Staphylococcus } \\
\text { aureus (UFC/g) }\end{array}$ & 5 & 2 & 5 & 3 & 5 & 1 & $\begin{array}{c}\mathrm{m}\left(10^{2}\right), \mathrm{M}\left(10^{3}\right) \\
(n: 5, c: 2)\end{array}$ \\
\hline $\begin{array}{l}\text { Salmonella sp } \\
\quad(\text { En } 25 \mathrm{~g})\end{array}$ & 5 & 0 & 5 & 0 & 5 & 0 & $\begin{array}{l}\text { Ausencia en } 25 \\
\text { g. }(n: 5, c: 0)\end{array}$ \\
\hline $\begin{array}{l}\text { Vibrio cholerae } \\
\quad \text { (En } 25 \mathrm{~g})\end{array}$ & 5 & 0 & 5 & 0 & 5 & 0 & $\begin{array}{l}\text { Ausencia en } 25 \\
\text { g. }(n: 5, c: 0)\end{array}$ \\
\hline $\begin{array}{l}\text { Vibrio } \\
\text { parahaemolyticus } \\
\quad(\text { En } 25 \mathrm{~g})\end{array}$ & 5 & 0 & 5 & 0 & 5 & 0 & $\begin{array}{l}\text { Ausencia en } 25 \\
\text { g. }(n: 5, c: 0)\end{array}$ \\
\hline
\end{tabular}

Los valores resaltados indican que han superado los límites máximos permisibles (LMP) por NTS $\mathrm{n}$ : número de unidades de muestra seleccionada al azar de un lote

c: número máximo de unidades de muestra que puede contener un número de microorganismos comprendidos entre " $\mathrm{m}$ " $\mathrm{y}$ " $\mathrm{M}$ " en un plan de muestreo. Si se detecta un número de unidades de muestra mayor a "c" se rechaza el lote

$\mathrm{m}$ : límite microbiológico que separa la calidad aceptable de la rechazable

$\mathrm{M}$ : los valores con recuentos microbianos superiores a $\mathrm{M}$ son inaceptables. El alimento representa un riesgo para la salud

Fuente: NTS N071- MINSA/DIGESA - V.01

Cuadro 2. Evaluación parasitológica y de $\mathrm{pH}$ en la carne de tres especies de peces $(\mathrm{n}=10$ por especie) provenientes del desembarque en el puerto de Pucallpa, Ucayali, Perú

\begin{tabular}{lccc}
\hline \multirow{2}{*}{ Especie } & Descarte parasitológico & \multicolumn{2}{c}{ Evaluación de $\mathrm{pH}$} \\
\cline { 3 - 4 } & & Promedio $\pm \mathrm{DE}$ & $\begin{array}{c}\text { Valor mínimo - Valor } \\
\text { máximo }\end{array}$ \\
\hline Boquichico & Negativo & $5.83 \pm 0.22$ & $5.73-6.1$ \\
Palometa & Negativo & $6.01 \pm 0.09$ & $5.91-6.15$ \\
Bagre & Negativo & $5.87 \pm 0.17$ & $5.68-6.14$ \\
\hline
\end{tabular}


Cuadro 3. Evaluación microbiológica del agua proveniente del puerto de Pucallpa, Ucayali, Perú

\begin{tabular}{cccc}
\hline \multirow{2}{*}{$\begin{array}{c}\text { Distancia de la } \\
\text { orilla del río } \\
(\mathrm{m})\end{array}$} & $\begin{array}{c}\text { Coliformes totales } \\
(\mathrm{NMP} / 100 \mathrm{ml})\end{array}$ & $\begin{array}{c}\text { Escherichia coli } \\
(\mathrm{NMP} / 100 \mathrm{ml})\end{array}$ & $\begin{array}{c}\text { Pseudomona } \mathrm{sp} \\
(\mathrm{NMP} / 100 \mathrm{ml})\end{array}$ \\
\cline { 2 - 4 } & $>23$ & $5.1(1.6-13)$ & $<1.1$ \\
$5-1$ & $>23$ & $6.9(2.5-15)$ & $2.2(0.37-8.1)$ \\
50 & $>23$ & $3.6(0.91-9.7)$ & $2.2(0.37-8.1)$ \\
\hline
\end{tabular}

Cuadro 4. Evaluación fisicoquímica del agua del puerto de Pucallpa, Ucayali, Perú

\begin{tabular}{cccccc}
\hline $\begin{array}{c}\text { Distancia de la } \\
\text { orilla del río } \\
(\mathrm{m})\end{array}$ & $\mathrm{pH}$ & $\begin{array}{c}\text { Conductividad } \\
(\mu \mathrm{s} / \mathrm{cm})\end{array}$ & $\begin{array}{c}\text { Parámetro } \\
(\mathrm{mg} \\
\left.\mathrm{CaCO}_{3} / \mathrm{l}\right)\end{array}$ & $\begin{array}{c}\text { Hierro } \\
(\mathrm{mg} \mathrm{Fe}++/ 1)\end{array}$ & $\begin{array}{c}\text { Turbiedad } \\
(\mathrm{UNT})\end{array}$ \\
\hline $0-1$ & 7.67 & 193.5 & 86 & 0.18 & 745.6 \\
50 & 8.09 & 233.7 & 96 & 0.55 & 27.48 \\
150 & 8.14 & 182.3 & 84 & 0.51 & 419.8 \\
\hline
\end{tabular}

Método: SMEWW-APHA-AWWA-WEF Ed.22 2012

UNT: Unidad Nefelométrica de turbiedad

aureus estuvo presente por encima al LMP en carne de palometa, mientras que Salmonella sp, Vibrio cholerae y Vibrio parahemolyticus estuvieron ausentes en todas las muestras (Cuadro 1). Los valores de $\mathrm{pH}$ de la carne estuvieron en el rango promedio apropiado y no se hallaron parásitos (Cuadro 2). En el agua se encontraron coliformes, E. coli y Pseudomona sp en niveles elevados (Cuadro 3). Los parámetros físicos químicos estuvieron dentro de los rangos normales (Cuadro 4) y en la evaluación parasitológica se encontraron organismos de vida libre (protozoarios, copépodos, rotíferos, nematodos) sin evidencia de hallazgos sobresalientes. En instalaciones, mobiliarios y manos de los manipuladores se encontró E. coli y recuentos elevados de coliformes (Figura 1).

\section{Discusión}

La contaminación microbiológica se encontró en todos los puntos evaluados de la cadena de comercialización pesquera (agua, instalaciones, embarcaciones, manipuladores y pescados). La extensión de la actividad tanto en el desembarque, en el comercio y el tránsito de personas en el puerto, conjuntamente con las medidas sanitarias deficientes sugieren ser los causantes del riesgo de contaminación cruzada constante hacia los productos hidrobiológicos. Los hallazgos relacionados a la caracterización sanitaria y su interrelación con la contaminación de pescados fueron similares al reporte de Martínez y Romero (2015). 


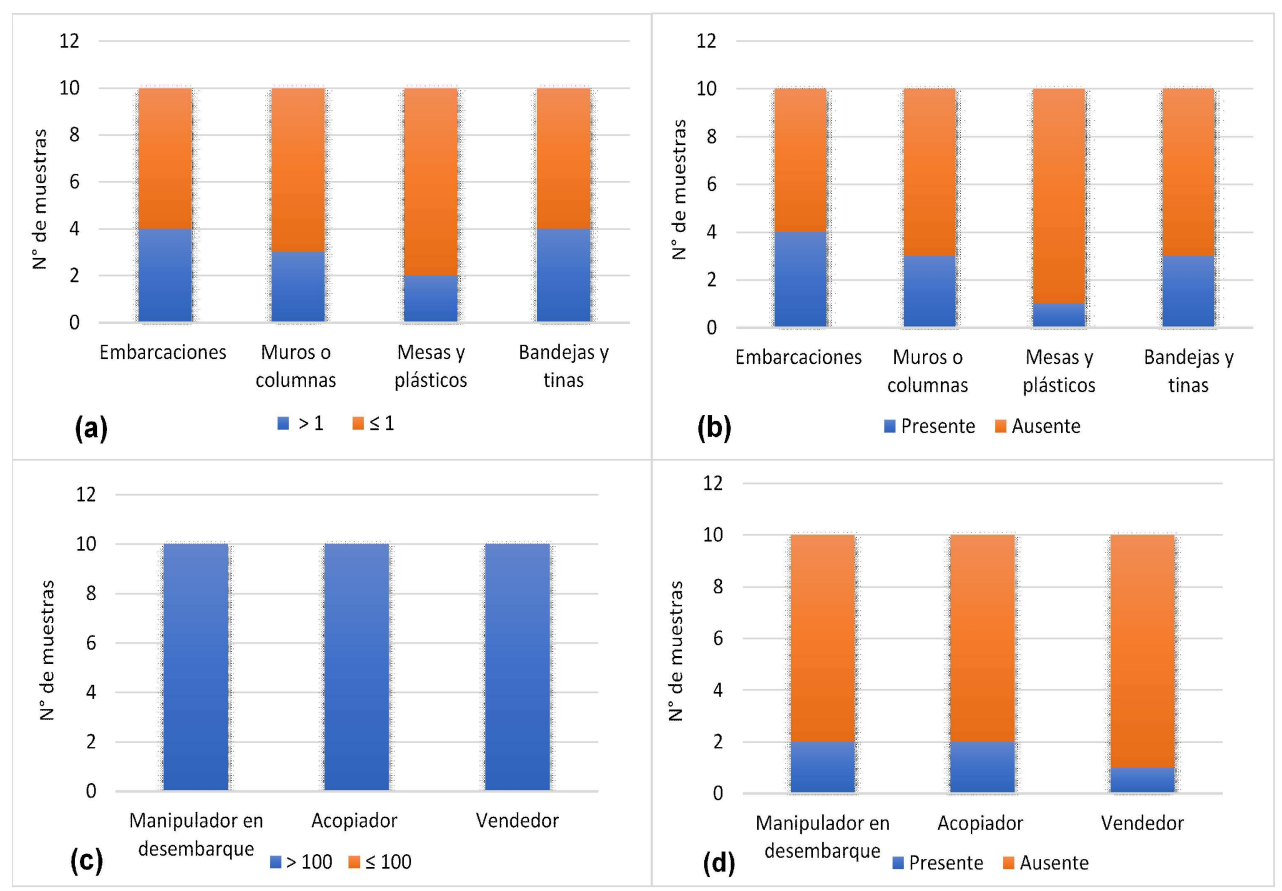

Figura 1. Análisis microbiológico en manos de manipuladores de pescado y en embarcaciones, instalaciones y mobiliario usados en la cadena de comercialización pesquera en el Puerto de Pucallpa, Ucayali (Perú). (a) Recuento de coliformes (UFC/ $\mathrm{cm}^{2} \mathrm{de}$ superficie); (b) Presencia de Escherichia coli en $100 \mathrm{~cm}^{2}$ de superficie en embarcaciones, instalaciones y mobiliario; (c) Recuento de coliformes en manos de manipuladores (UFC/mano); (d) Presencia de Escherichia coli en manos de manipuladores.

Límite permisible de coliformes totales en superficies regulares: $<1 \mathrm{UFC} / \mathrm{cm}^{2}$ Límite permisible de coliformes totales en superficies regulares: $<100 \mathrm{UFC} / \mathrm{manos}$ Fuente: [MINSA] Ministerio de Salud. 2007. Guía técnica para el análisis de superficies en contacto con alimentos y bebidas. Resolución Ministerial N. ${ }^{\circ} 461-2007 / M I N S A$

Los resultados de los análisis microbiológicos en la carne de pescado se contrastan a los obtenido por Gabancho (2014), quien determinó una baja calidad higiénica en cuatro especies de pescado comercializados en un mercado de la ciudad de Tingo María, Perú. Por otra parte, Vásquez et al. (2018) determinaron que los niveles de UFC/g de $E$. coli y Staphylococcus aureus superaron los niveles permitidos por la norma técnica en muestras de pescados y mariscos de varios mercados de la ciudad de Huánuco. En el presente estudio, los niveles de Staphylococcus spp y aerobios mesófilos en la carne cruda de palometa y bagre, respectivamente, estuvieron por encima a los límites máximos permisibles según el reglamento de SANIPES (2016a), haciéndolos no aptos para el consumo humano (Cuadro 1).

Los resultados evidencian que el bagre posee el mayor grado de contaminación bacteriana, en comparación con las otras especies en estudio. Según Corrales et al. 
(2011), estos hallazgos podrían deberse a que el bagre posee un proceso de cortado antes de su venta, lo que incrementa la contaminación cruzada a través del contacto directo con el manipulador, las superficies y los utensilios empleados. La tradición del consumo de pescado crudo, ligeramente cocido o marinado no garantiza la eliminación de patógenos. Además de E. coli y Salmonella sp, Staphylococcus aureus es un agente infeccioso y toxigénico comúnmente encontrado en los alimentos, tanto en forma natural en productos crudos o añadidos por el hombre durante una inadecuada manipulación (Da Silva et al., 2008).

Con respecto a la ausencia de Salmonella sp (Cuadro 1), se ha reportado que esta bacteria no es un contaminante biológico originario de los peces, sino que puede ser introducido a la cadena de comercialización debido a la mala calidad del agua por contaminación fecal o manejo inapropiado de los productos hidrobiológicos (Fernandes et al., 2018). No se dispone de muchos estudios sobre la proliferación de Salmonella sp en productos hidrobiológicos (Kumar et al., 2015), de allí que no sea posible afirmar la total ausencia de esta bacteria.

La ausencia de Vibrio cholerae y $V$. parahaemolyticus (Cuadro 1) pudo deberse a que estas bacterias poseen requerimientos específicos en cuanto a la concentración de sal en el medio donde han de desarrollarse. Si bien la distribución de la bacteria depende de la región y de diversos factores bióticos y abióticos de repercusión global, se ha descrito que diversas especies pueden encontrarse principalmente y de forma natural en ambientes marinos y zonas costeras (Aliaga et al., 2010; Yücel y Balci, 2010), lo que se opone a las condiciones del presente estudio, donde las aguas son dulces. Más aún, esta variabilidad ha sido reportada en la región Lima donde Aliaga et al. (2010) identificaron a $V$. parahaemolyticus $\mathrm{O} 3: \mathrm{K} 6$ en pescados y bivalvos de un mercado pesquero, mientras que Carbajal et al. (2003) señalaron la au- sencia de $V$. cholerae en productos hidrobiológicos del mercado mayorista pesquero de Ventanilla.

En cuanto al $\mathrm{pH}$ de la carne, según lo indicado por la Organización Mundial de la Salud (OMS), el pH de la carne estuvo en el rango promedio apropiado en las tres especies (5.48-6.35), e indican un estado apto de frescura del pescado. Por otra parte, y de acuerdo con la metodología aplicada por Conroy (2006), no se hallaron parásitos en las muestras evaluadas (Cuadro 2).

Los parámetros microbiológicos y parasitológicos obtenidos en las muestras de agua del puerto (Cuadro 3) fueron similares a los obtenidos por Ayllón y Pérez (2015), quienes determinaron la interrelación entre los agentes patógenos presentes en el agua del río Itaya en Loreto y la enfermedad prevalente en la población. Los niveles elevados de E. coli en todas las muestras pueden deberse al elevado nivel de contaminación del río Ucayali. La OEFA (2016) realizó el monitoreo de parámetros de campo, fisicoquímicos y microbiológicos en diversos puntos de este río, demostrando altos niveles de contaminación por coliformes termotolerantes. Consecuentemente, E. coli es un importante indicador de contaminación fecal reciente; además, abre la posibilidad de la presencia de otros patógenos entéricos e influye en las pobres condiciones de higiene durante la manipulación de los alimentos (Ekici y Dümen, 2019).

Los parámetros fisicoquímicos del agua estuvieron dentro de los rangos aceptables (Cuadro 4). Los resultados contrastan con los hallazgos de Vásquez (2018), quien determinó niveles elevados de plomo en el agua del río Ucayali, mientras que en este estudio estaban por debajo de los niveles máximos otorgados por el Codex Alimentarius (FAO/ OMS, 2015). Por otra parte, Morán e Hidalgo (2016) reportaron contaminantes inorgánicos elevados en Puerto Pizarro, en el norte del Perú, debido a la eliminación de residuos a las fuentes de agua, producto de la 
actividad de empresas langostineras, del sector agrícola y el desembarque pesquero.

Los recuentos altos de coliformes y de E. coli en instalaciones, mobiliario, embarcaciones y manos de manipuladores (Figura 1a,b) reflejan deficientes condiciones higiénicas en estos puntos, y pueden estar relacionados con el agua de donde provienen el pescado y pueden representar un riesgo para la salud pública (Corrales et al., 2011). Las personas involucradas en la cadena de comercialización no aplican buenas prácticas de manipulación ni usan indumentaria adecuada para las actividades de expendio en el puerto, lo cual puede favorecer la contaminación cruzada de los productos hidrobiológicos (Quijada, 2016). En este aspecto, Vásquez et al. (2018) encontraron que el $84 \%$ de vendedores de varios mercados de Huánuco no utilizaba vestimenta apropiada, $72 \%$ de los utensilios no era adecuado para la manipulación de los alimentos y solo $14 \%$ de los comerciantes recurrían a la aplicación de hielo para mantener la cadena de frío en los productos hidrobiológicos.

Los desembarcaderos pesqueros artesanales y las embarcaciones también son fuente de contaminación, no solo para el producto hidrobiológico, sino para lugares circundantes (Figura $1 \mathrm{c}, \mathrm{d}$ ). Se requiere realizar inversiones en su infraestructura para evitar que se siga usando agua contaminada para el proceso de lavado del pescado (Ramírez e Hishihara, 2008), así como implementar un Análisis de Peligros y Puntos Críticos de control (APPC) para garantizar la inocuidad de los productos pesqueros (De las Cuevas, 2006).

En el capítulo IX de los «Lineamientos para el Expendio de Pescados, Mariscos y/o Productos Hidrobiológicos en Mercados de Abasto Mayoristas y Minoristas» (SANIPES, 2016b), se establecen los requisitos operativos de los puestos de venta que señalan que los productos deben ser recibidos, manipulados, almacenados y expuestos a los consumidores de forma que se reduzcan al mínimo los posibles peligros y defectos de inocuidad alimentaria, manteniendo la calidad esencial. Esto incluye indicaciones sobre la indumentaria de trabajo adecuada, que incluye mandil de color claro, delantales impermeables, calzado de jebe, protectores de cabello y guantes en buen estado. Además, se describe las características de las condiciones de exhibición y venta minorista de estos alimentos, enfatizando en la necesidad de la cadena de frío y prevención de la contaminación cruzada.

La cadena de comercialización de productos hidrobiológicos posee puntos críticos donde son necesarias las buenas prácticas para evitar que se afecten las condiciones físicas, químicas y microbiológicas de estos alimentos, disminuyendo el riesgo para la salud del consumidor (Corrales et al., 2011). No obstante, la falta de programas establecidos de desinfección y sanitización en el puerto podría originar la persistencia de agentes bacterianos en las instalaciones y mobiliario, lo que puede generar igualmente la contaminación cruzada de los productos hidrobiológicos que son expendidos en las riberas del río Ucayali. Por este motivo, la implementación de un plan operativo de limpieza y sanitización es importante (Córdova, 2013).

\section{Conclusiones}

- La comercialización pesquera en el puerto de Pucallpa es artesanal, con una infraestructura básica, y pobres prácticas sanitarias.

- Los puntos críticos de contaminación comprenden las fuentes de agua, instalaciones y mobiliario, embarcaciones y manipuladores.

- La contaminación microbiológica es alta en las instalaciones y en los manipuladores, y moderada en los pescados. 


\section{Literatura Citada}

1 Aliaga R, Miranda J, Zevallos J. 2010. Aislamiento e identificación de Vibrio parahaemolyticus O3: K6 en pescados y moluscos bivalvos procedentes de un mercado pesquero de Lima, Perú. Rev Med Hered 21: 139-145.

2 Ayllón TZ, Pérez AM. 2015. Contaminación del agua del río Itaya por agentes biológicos patógenos y su impacto en la salud humana. Tesis de Magíster. Loreto, Perú: Univ. Nacional de la Amazonía Peruana. $141 \mathrm{p}$.

3 Barba G, Ramírez J, Cortés J, Sánchez I, Ruelas J, Moreno J. 2012. Contenido de histamina y calidad microbiológica de pescado comercializado en Mazatlán, Sinaloa. Biotecnia 14: 3 - 12.

4 Carbajal MT, Rabelo P, Gonzáles CS, Ayala ME. 2003. Evaluación microbiológica de productos adquiridos en el mercado mayorista pesquero de Ventanilla - Perú. Rev Cubana Salud Pública 29: 121-123.

5 Conroy G 2006. Principales enfermedades en peces de cultivo de la Amazonía.Lima, Perú: FAO. 56 p.

6 Córdova GI, 2013. Elaboración del plan de limpieza y sanitización para mejorar la calidad de productos pesqueros comercializados en el local PROMAR ubicado en la ciudad de Ambato. Diplomado. Ecuador: Univ. Técnica de Ambato. 43 p.

7 Corrales L, Alvarado M, Castillo L, Camacho Y. 2011. Estudio bacteriológico de la calidad del pescado fresco, bagre (Pseudoplatystoma sp) y mojarra roja (Oreochromis sp) comercializado en el municipio de El Colegio, Cundinamarca (Colombia). NOVA 9 (16): 149-157.

8 Da Silva ML, Matté GR, Leal PM, Matté MH. 2008. Occurrence of pathogenic microorganisms in fish sold in Sao Paulo, Brazil. J Food Safety 30: 94110. doi: 10.1111/j.1745-4565.2009.-00192x
9 Da Silva N, Hiromi M, Amstalden J, Ferraz De Arruda N, Da Silva M, Romeiro R. 2013. Microbiological examination methods of food and water. Sao Paulo: Varela. 436 p.

10 De las Cuevas IV. 2006. APPC aplicado a la comercialización de pescados y mariscos. Guía básica de aplicación. Madrid: Ideas propias. $80 \mathrm{p}$.

11 Ekici G, Dümen E. 2019. Escherichia coli and food safety. The universe of Escherichia coli. Intech Open. 17 p. doi: 10.5772/intechopen.8237512

12 [FAO] Organización de las Naciones Unidas para la Agricultura y la Alimentación. 1998. El pescado fresco: su calidad y cambios en su calidad. Internet. Disponible en: http://www.fao.org/ docrep/v7180s/v7180s00.htm

13 [FAO] Food and Agriculture Organization of the United Nations. 2014. El estado mundial de la pesca y la acuicultura. Roma: FAO. $253 \mathrm{p}$.

14 [FAO/OMS] Organización de las $\mathrm{Na}$ ciones Unidas para la Agricultura y la Alimentación / Organización Mundial de la Salud. 2015. Norma general para los contaminantes y las toxinas presentes en los alimentos y piensos. Codex Alimentarius. Normas internacionales de los alimentos. CODEX STAN 193- 2015. Enmienda 2010, 2012,2013, 2104,2015.62p.

15 Fernandes DVGS, Silva V, Da Cunha A, De Souza E. 2018. Salmonella spp in the fish production chain: a review. Ciência Rural 48: 1-11. doi: http:// dx.doi.org/10.1590/0103-8478cr20180141

16 Gabancho TF. 2014. Evaluación de la calidad higiénica de 4 especies de pescado de mayor consumo, expendidos en el mercado de Tingo María. Tesis de Ingeniero Zootecnista. Tingo María, Perú: Univ. Nacional Agraria de la Selva. 139 p.

17 [IMARPE] Instituto del Mar del Perú. 2017. Resumen mensual de la pesquería comercial en Pucallpa - Ucayali. 
Seguimiento Biológico. 01 al 31 marzo. 2017. [Internet]. Disponible en: http:// www.imarpe.pe/imarpe/archivos/reportes/imarpe_reporte_mensual_ucayali_marzo_2017.pdf

18 Kumar R, Datta TK, Lalitha KV. 2015. Salmonella grows vigorously on seafood and expresses its virulence and stress genes at different temperature exposure. BMC Microbiol 15: 1-10. doi: 10.1186/ s12866-015-0579-1

19 [MINSA] Ministerio de Salud. 2007. Guía técnica para el análisis de superficies en contacto con alimentos y bebidas. Resolución Ministerial №461-2007/ MINSA. [Internet]. Disponible en: http:/ /www.sanipes.gob.pe/normativas/ 8_RM_461_2007_SUPERFICIES.pdf

20 Martínez $R B$, Romero AM. 2015. Evaluación de la calidad microbiológica de pescado crudo comercializado en el muelle del puerto de La Libertad. Tesis de Químico Farmacéutico. San Salvador: Univ. de El Salvador. 223 p.

21 Morán B, Hidalgo A. 2016. Contaminantes en la bahía Puerto Pizarro. Rev Invest Cient Manglar 13: 43-51.

22 [OEFA] Organismo de Evaluación y Fiscalización Ambiental. 2016. Niveles de contaminación de los cuerpos de agua en el departamento de Ucayali. [Internet] Disponible en: http://www.oefa.gob.pe/wp-content/uploads/2016/ 04/Tema-3.-Problematica-contaminacion-agua-en-Ucayali.pdf

23 [OMS] Organización Mundial de la Salud. 2015. Inocuidad de los alimentos. Nota descriptiva N. ${ }^{\circ} 399$. [Internet]. Disponible en: http://www.who.int/ mediacentre/factsheets/fs399/es/

24 [PRODUCE] Ministerio de la Producción. 2011. Texto único ordenado del reglamento de inspecciones y sanciones pesqueras y acuícolas - RISPAC. Decreto Supremo N. ${ }^{\circ}$ 019-2011. Lima. [Internet]. Disponible en: http:// www2.produce.gob.pe/dispositivos/pu- blicaciones/2011/diciembre/ds019-2011produce.pdf

25 [PRODUCE] Ministerio de la Producción. 2015. Consumo per-cápita de pescado a nivel nacional. [Internet]. Disponible en: http://www.produce.gob.pe/ index.php/k2/noticias/item/283-produceconsumo-per-capita-de-pescado-a-nivelnacional-crecio-de-10-a-12-3-kilos

26 Quijada RM. 2016. Identificación y cuantificación de coliformes totales y Escherichia coli en las zonas de amortiguamiento Las Delicias y Parachique en la Bahía de Sechura - Piura. Tesis de Médico Veterinario Zootecnista. Univ. Peruana Cayetano Heredia. 28 p.

27 Ramírez, R, Hishihara H. 2008. Manual de buenas prácticas de manejo y aseguramiento de la calidad de productos pesqueros. El Salvador: Centro de Desarrollo de la Pesca y Acuicultura. Cendepesca. $56 \mathrm{p}$.

28 [SANIPES] Organismo Nacional de Sanidad Pesquera. 2016a. Ministerio de la Producción. Guía Fiscalización Pesquera y Acuícola. Resolución N. ${ }^{\circ}$ 001- 2016. SANIPES. DNSPA. $32 \mathrm{p}$.

29 [SANIPES] Organismo Nacional de Sanidad Pesquera. 2016b. Lineamiento para el expendio de pescados, mariscos y/o productos hidrobiológicos en mercados de abasto mayoristas y minoristas. RD Nº 017-2016-SANIPESDSNPA. [Internet] Disponible en: http:/ /www.-sanipes.gob.pe/procedimientos/ 8_RESOLUCION-_DIRECTORAL_N_017_2016_-SANIPESDSNPA.pdf

30 [SMEWW-APHA-AWWA-WE F] American Public Health Association - American Water Works Association - Water Environment Federation. 2012. Standard Methods for examination of water and wastewater. $22^{\text {nd }} \mathrm{ed}$. Washington: American Public Health Association. $1360 \mathrm{p}$. 
31 Tello S, Bayley P. 2001. La pesquería comercial de Loreto con énfasis en el análisis de la relación entre captura y esfuerzo pesquero de la flota comercial de Iquitos, cuenca del Amazonas (Perú). Folia Amazónica 12: 123-139.

32 Vásquez GA. 2018. Calidad sanitaria de las especies: Prochilodus nigricans (Boquichico), Pimelodus blochii (Bagre) y Mylossoma duriventre (Palometa) por presencia de plomo $(\mathrm{Pb})$ en las aguas del río Ucayali; tramo: confluencia del río Tambo con el río Urubamba hasta la desembocadura del río Pachitea, en la región
Ucayali - julio 2017. Tesis de Ingeniero Ambiental. Pucallpa. Univ. Nacional de Ucayali. 69 p.

33 Vásquez JM, Tasayco WR, Chuquiyauri MA, Apac S. 2018. Evaluación micro-biológica de pescados y mariscos expendidos en mercados de la ciudad de Huánuco. Rev Inv Valdizana 12: 75-82. doi: https://doi.org/10.33554/riv.12.2.142

34 Yücel N, Balci S. 2010. Prevalence of Listeria, Aeromonas, and Vibrio species in fish used for human consumption in Turkey. J Food Prot 73: 380-384. 